\title{
NOTA
}

\section{LIBERAÇÃO DE NUTRIENTES DURANTE A DECOMPOSIÇÃO DE PALHA DE AVEIA PRETA (Avena strigosa) COM DIFERENTES TEORES DE SILÍCIO(1)}

\author{
L. S. SILVA(2) \& H. BOHNEN ${ }^{(3)}$
}

\begin{abstract}
RESUMO
O Si absorvido pelas plantas é, em sua maior parte, depositado na parte externa da parede celular de folhas como uma camada de sílica amorfa $\left(\mathrm{SiO}_{2} \cdot \mathrm{nH}_{2} \mathrm{O}\right)$ e poderia afetar a decomposi ção da pal ha no solo. Com o objetivo de avaliar o efeito da presença deste elemento no tecido vegetal sobre a decomposi ção da pal ha, foi desenvolvido um experimento. Nesse experimento, a parte aérea de plantas de aveia preta, cultivadas em solução nutritiva com e sem adição de Si, foi incubada em tubos de PVC com areia e solo. Aos 6, 14, 30, 66, 100 e 182 dias, foram realizadas percolações com água destilada e determi nados os teores de Si, carbono orgâni co solúvel, N mineral, $\mathrm{Ca}, \mathrm{Mg}, \mathrm{Na}$ e K. Os resultados dos teores dos elementos na água percolada em cada período foram convertidos em quantidade liberada por $\mathbf{k g}$ de substrato (solo ou areia) e acumulados no tempo para serem utilizados como índices da decomposição da palha. E m todos os parâmetros avaliados, não houve diferença significativa entre a palha c/Si e s/Si, exceto para o teor de Si e este somente quando a palha foi decomposta na areia. $\mathbf{O}$ silício absorvido pelas plantas de aveia preta, quando comparado com plantas cultivadas sem adição deste elemento, não alterou a liberação de carbono e nutrientes presentes na água de percolação durante o período de 182 dias da decomposição da palha.
\end{abstract}

Termos de indexação: sílica, aveia preta, percolação.

(1) Trabalho apresentado como resumo no XXVII Congresso Brasileiro de Ciência do Solo (11 a 16/07/1999) Brasília (DF). Recebido para publicação em setembro de 1999 e aprovado em dezembro de 2000.

(2) Doutorando em Ciência do Solo, Departamento de Sol os da Faculdade de Agronomia, Universidade Federal do Rio Grande do Sul UFRGS. Caixa Postal 776, CEP 90001-970 Porto Alegre (RS). E-mail: Issilva@vortex.ufrgs.br

(3) Engenheiro-Agrônomo, PhD. Colaborador convidado. Departamento de Solos, Faculdade de Agronomia, UFRGS. E-mail: bohnen@conex.com.br 


\title{
SUMMARY: OAT STRAW (Avena strigosa) NUTRIENT MINERALIZATION WITH DIFFERENT SILICON COMPOSITION
}

\begin{abstract}
Most of thesilicon absorbeb by plants remains deposited on theexternal part of thecell walls as a layer of amorphous silica $\left(\mathrm{SiO}_{2} \cdot \mathrm{nH} \mathrm{H}_{2} \mathrm{O}\right)$, probably affecting straw mineralization in soils. An experiment was performed with theaerial part of oat plants, cultivated in nutrient solution with and without silicon addition, to evaluatethis hypothesis. Dried aerial parts of oat plants tissue was mixed with soil or washed quartz sand and placed in PVC tubes. Distilled water was percolated through the mixture at 6, 14, 30, 66, 100 and 182 days after the beginning of theexperiment. Silicon, solubleorganic carbon, mineral nitrogen, calcium, magnesium, sodium and potassium wereanalysed in theleachetes. Results werecal culated as theamount of the el ement liberated from thetissue per $\mathrm{kg}$ of substrate (soil or sand) and interpreted as an indication of straw mineralization. No differences werefound between the amounts percolated from the oat straw with and without silicon, except for silicon in the sand treatments. It was concluded that, during the period considered (182 days), a greater silicon amount in the oat straw did not affect its mineralization.
\end{abstract}

Index terms: silica, oat, percolation.

\section{NTRODUÇÃO}

O manejo adequado dos resíduos culturais é uma ferramenta importante na conservação dos solos e na recuperação da capacidade produtiva de áreas degradadas (Miel niczuk, 1988). Atualmente, com a utilização de sistemas mais conservacionistas de preparo do solo, especialmente o sistema plantio direto, altera-se a dinâmica da decomposição da matéria orgânica e ocorre acúmulo de resíduos culturais sobre a superfície. A pal ha queéadicionada ao solo sofre decomposição pel os microrganismos e ocorre a mineralização dos el ementos que compõem o material orgânico, liberando-os para a solução do solo. Na solução, os elementos entram em equilíbrio com as outras fases do solo e a análise da água de percolação poderia servir como um índice para avaliar indiretamentea dinâmica que envolvea sua liberação e a interação com outros componentes do sistema.

Nesse contexto, a qualidade química do material orgânicoé um dos fatores que podem influir na taxa de decomposição da pal ha ena conseqüenteliberação dos nutrientes mineral izados. O teor de sílica $\left(\mathrm{SiO}_{2}\right)$ já tem sido avaliado na caracterização da qualidade de resíduos vegetais de diferentes espécies submetidas à decomposiçãono sol o (Tian et al., 1992). Entretanto, os autores não conseguiram concluir a respeito do efeito isol ado do Si sobre a decomposição da palha. I sto se deve principalmente ao fato de as espécies com diferentes teores de Si também apresentarem diferentes teores deoutros componentes importantes os quais influem sobremaneira na decomposição, como celulose elignina e a relação C/ $\mathrm{N}$, daí a dificuldade em estudar o papel do Si neste processo.
O Si constitui aproximadamente $28 \%$ da composição da crosta terrestre e é o el emento mais abundante após o oxigênio (Heinen \& Oehler, 1979). Nãoéconsiderado um el emento essencial às plantas superiores, mas tem sido citado como benéfico para o crescimento e, em algumas condições e para algumas espécies, pode ser considerado como essencial (Marschner, 1995). Este el emento é absorvido pelas raízes das plantas na forma deácido monossilícico $\mathrm{Si}(\mathrm{OH})_{4}$, podendo apresentar concentrações muito altas na parte aérea, em comparação com a mai oria dos nutrientes essenciais. A concentração nas plantas é extremamente variável, podendo atingir até $10 \%$ da matéria seca em espécies como o arroz e menor que 0,5\% em algumas leguminosas (Marschner, 1995). Essas diferenças ocorrem porque, em espécies que acumulam Si (arroz, trigo e cevada), o elemento é absorvido ativamente, enquanto, em outras espécies, como aveia, este elemento éabsorvido passi vamente via fluxo de massa (Mayland et al., 1991).

A maior parte do Si absorvido pelas plantas (90 a $95 \%$ ) é depositada na parte externa da parede celular das células como uma fina camada de sílica amorfa (opala biogênica, $\mathrm{SiO}_{2} \cdot \mathrm{nH}_{2} \mathrm{O}$ ), após a perda da água pela transpiração, principalmente na epiderme das folhas (Lewin \& Reimann, 1969). Esta camada que recobre a parede celular das células da epiderme em ambas as superfícies das folhas, juntamentecom a camada de cutícula, funciona como uma barreira efetiva contra a perda de água pela transpiração e como proteção contra infecções por fungos (Lewin \& Reimann, 1969; Marschner, 1995).

$\mathrm{O}$ efeito de altos teores de $\mathrm{SiO}_{2}$ no tecido vegetal é conhecido na alimentação de ruminantes, pela redução da digestibilidade e palatabilidade de 
forragens, principalmente em palha de arroz (van Soest, 1981). Assim, o Si absorvido pelas plantas e depositado na paredecelular poderia funcionar como uma espécie de barreira, reduzindo a perda e, ou, o acesso ao material celular durante a decomposição da palha no solo.

O objetivo deste trabalho foi estudar se concentrações diferentes de Si no tecido vegetal de plantas de aveia alteram a liberação de carbono e nutrientes durante a decomposição da palha em areia e solo, medida por meio da análise da água de percolação.

\section{MATE RIAL E MÉTODOS}

Plantas de aveia preta (Avena strigosa), cultivar Comum (RS), foram cultivadas por 75 dias em vasos de sete litros que continham solução nutritiva compl eta (com as seguintes concentrações de $\mathrm{N}-\mathrm{NO}_{3}$, $\mathrm{N}-\mathrm{NH}_{4}, \mathrm{P}, \mathrm{K}, \mathrm{Ca}, \mathrm{Mg}, \mathrm{S}, \mathrm{Cl}, \mathrm{B}, \mathrm{Cu}, \mathrm{Fe}, \mathrm{Mn}, \mathrm{Moe} \mathrm{Zn}$ de 3,$0 ; 1,5 ; 0,5 ; 2,0 ; 1,5 ; 1,0 ; 1,0 ; 3,0 ; 0,023 ; 0,0047 ; 0,18$; 0,$0047 ; 0,00011 ; 0,0015 \mathrm{mmol} \mathrm{L}^{-1}$, respectivamente) com e sem adição de Si (chamadas, neste trabalho, de $\mathrm{C} / \mathrm{Si}$ e $\mathrm{s} / \mathrm{Si}$, respectivamente) na forma de sílica amorfa finamente moída $(<0,1 \mathrm{~mm})$, equivalente a $1 \mathrm{~g} \mathrm{vaso}^{-1}$, mantendo uma concentração de equilíbrio na solução de $4 \mathrm{mg} \mathrm{L}^{-1}$ de Si.

A parte aérea das plantas foi coletada, seca em estufa e moída. Da palha moída, foi selecionada a fração entre 0,1 e 0,5 mm para ser misturada, na quantidade equivalente a $5 \mathrm{~g} \mathrm{~kg}^{-1}$, com areia (quartzítica lavada com água destilada até condutividade elétrica constante) e solo (seco ao ar, peneirado em mal ha de $2 \mathrm{~mm}$ e pertencente à classe Argissolo Vermelho distrófico típico) que apresentavam pH em água (1:1) de 7,3 e 4,5 e teor de carbono de 0,2 e 9,4 $\mathrm{g} \mathrm{kg}^{-1}$, respectivamente.

As características químicas das pal has $c / S i$ es/Si encontram-se no quadro 1 , anal isadas após digestão com mistura de $\mathrm{H}_{2} \mathrm{SO}_{4}$ e $\mathrm{H}_{2} \mathrm{O}_{2}$ e determinação dos elementos, conforme descrição de Malavolta et al. (1989). O Si total foi analisado por espectrometria deabsorção atômica após digestão do teci do com uma mistura de $\mathrm{HF}, \mathrm{HNO}_{3}$ e $\mathrm{H}_{2} \mathrm{O}_{2}$ (250 mg de amostra, $0,5 \mathrm{~mL}$ de $\mathrm{H}_{2} \mathrm{O}, 5 \mathrm{~mL}$ de $\mathrm{HNO}_{3}, 0,5 \mathrm{~mL}$ de $\mathrm{H}_{2} \mathrm{O}_{2}$ e $2 \mathrm{~mL}$ deHF) em recipiente detefl on hermeticamente fechado e uso de microondas DET 100, com a seguinte programação de tempo $(\min ): 5,1,4,1,3$ nas respectivas potências (watts): 400, 790, 320, 790 e 000, conforme recomendação do fabricante (Provecto, s/d).

As amostras do solo ou da areia foram misturadas com cada tipo de pal ha e, em duas repetições, foram colocadas em tubo de PVC de $50 \mathrm{~mm}$ de diâmetro com $10 \mathrm{~cm}$ de altura até completar o volume dos tubos, tendo na parte inferior um tampão perfurado que continha uma tela de nylon $(<0,1 \mathrm{~mm})$ e $1 \mathrm{~cm}$ de areia. Também foram utilizados tubos somente com sol o ou areia, sem palha. E m cada tubo com areia foram adicionados $2 \mathrm{~mL}$ de solução do solo, extraída por centrifugação, para fornecer microrganismos para decomposi ção do material. A areia e o solo nos tubos foram umedecidos com água destilada até atingir 14,5 e 12,0\% de umidade gravimétrica, respectivamente, e mantidos em temperatura ambiente durante o período do experimento. A cada 10-15 dias, o teor de umidade foi mantido por meio de pesagens e adição de água destilada.

Aos 6, 14, 30, 66, 100 e 182 dias, foram realizadas percolações pela adição de $20 \mathrm{~mL}$ de água destilada e aplicada uma sucção (0,7 atm), utilizando uma bomba de vácuo conectada a um frasco kitassato que dispunha, na parte superior, de um funil revestido desilicone para encaixar o tubo de PVC, até recol her aproximadamente $20 \mathrm{~mL}$ de percolado.

$\mathrm{Na}$ água percolada, foram determinados o $\mathrm{pH}$ ea condutividade elétrica (CE), eretirada uma alíquota para análise de carbono orgânico solúvel e particulado menor que $0,1 \mathrm{~mm}$ por colorimetria $(580 \mathrm{~nm})$ após digestão da amostra por $4 \mathrm{~h}$ a $60^{\circ} \mathrm{C}$ com uma mistura sulfocrômica (relação amostra:mistura de 1:1) de $\mathrm{K}_{2} \mathrm{Cr}_{2} \mathrm{O}_{7} 1,25 \mathrm{~mol} \mathrm{~L}^{-1}$ contendo $80 \mathrm{~mL}$ de $\mathrm{H}_{2} \mathrm{SO}_{4}$ concentrado com uso de um fator 1,35 em relação à curva de glicose, procedimento correlacionado $(r=0,997)$ com o método descrito em Moore (1985). O restante do percolado foi filtrado com filtro 0,2 $\mu \mathrm{m}$ versapor (Gelman Sciences Inc.) para análises dos teores de $\mathrm{N}$ mineral (destilação em micro-Kjeldahl), Ca, Mge Si (espectrometria de absorção atômica), e Na e K (fotometria de chama).

Para corrigir a diferente quantidade de substrato nos tubos, as quantidades dos el ementos liberados em cada período, considerando a concentração no percolado e a massa de substrato em cada tubo, foram convertidas em mg kg-1 de substrato (sol o ou areia) para ser utilizado como índices da sua liberação durante a decomposição da palha. Os valores das médias de cada percolação no sol o e na areia foram acumulados no tempo. Os tratamentos

\section{Quadro 1. Características químicas da palha de aveia preta (fração entre 0,1 e $0,5 \mathrm{~mm}$ ) cultivada em solução nutritiva com e sem adição de Si}

\begin{tabular}{lllllllll}
\hline Palha & Si & $\mathbf{C}$ & $\mathbf{N}$ & $\mathbf{P}$ & $\mathbf{K}$ & $\mathbf{C a}$ & $\mathbf{M g}$ & $\mathbf{N a}$ \\
\hline & \multicolumn{10}{c}{$\mathrm{g} \mathrm{kg}^{-1}$} \\
Sem Si & 1,4 & 419 & 37 & 8,3 & 52 & 5,4 & 3,6 & 4,9 \\
Com Si & 5,7 & 408 & 33 & 8,0 & 49 & 4,5 & 3,5 & 5,2
\end{tabular}


foram arranjados em um fatorial cruzado fixo completamente casualizado, considerando como fatores o substrato (solo eareia) ea pal ha (sem pal ha, pal ha s/Si e pal ha $\mathrm{C} / \mathrm{Si}$ ). Após a análise de variância da interação substrato vs pal ha $(P<0,05)$, as médias dos tratamentos foram comparadas pela Diferença Mínima Significativa (DMS) em cada período de avaliação, obtida pelo teste de Tukey a 5\%.

\section{RESULTADOSE DISCUSSÃO}

Os valores da quantidade liberada de Si, acumulados ao longo do período de avaliação, encontram-se na figura 1 . Na areia, a palha c/Si liberou maior quantidade de Si em relação a palha s/Si em todos os períodos de avaliação, resultado da diferente acumulação do elemento no tecido das plantas de aveia (Quadro 1). Korndörfer et al . (1999) encontraram relação significativa entre a disponibilidade deSi no solo, avaliada por diferentes métodos, e a acumulação de Si pela parte aérea de plantas de arroz. Apesar de a aveia absorver Si passivamente (Mayland et al., 1991), o cultivo das plantas com esem a adi ção deSi na sol ução nutritiva refletiu no teor no tecido e na quantidade liberada durante a decomposição da palha. Entretanto, as quantidades percoladas na areia são parecidas e correspondem a 34 e 39\% do Si adicionado pela pal ha $\mathrm{s} / \mathrm{Si}$ e $/ \mathrm{Si}$, respectivamente.

A maior taxa de liberação pela palha $c / S i$ nos primeiros 30 dias ( $57 \%$ do total percolado na areia) pode estar relacionada com formas de ácido silícico livre ou compostos de Si de baixo peso molecular, constituindo material citoplasmático (Lewin \& Reimann, 1969; Ma \& Takahashi, 1989). Entre os 30 e 182 dias de decomposi ção, a liberação do elemento ocorreu em uma taxa constante, o que pode estar associado à mineralização dos constituintes do tecido vegetal, pois, de acordo com Lewin \& Reimann (1969), parte da sílica na planta encontra-se fortemente ligada à celul ose e só pode ser separada desta após a celulose ser mineralizada.

Quando decomposta no solo, a palha c/Si apresentou no percolado somente $36 \%$ da quantidade de Si liberada na areia após os 182 dias de decomposição e, neste período, não foi significativamentediferenteda liberada pela pal ha s/Si ou mesmo nosol osem adição de pal ha. Essecomportamento pode ser atribuído à presença de óxidos e filossilicatos, comuns no sistema solo, que apresentam reações de adsorção do el emento na superfície desses minerais, exercendo papel determinante na solubilidade doSi (Elgawhary \& Lindsay, 1972; Drees et al., 1989). Além disso, o produto de solubilidade da sílica é baixo (Drees et al., 1989) e, portanto, pode ser facilmente atingido na solução do solo.

Para o carbono orgânico e o nitrogênio mineral, as quantidades liberadas pela pal ha c/Si na areia e no sol o não foram significativamente diferentes das quantidades liberadas pela pal ha s/Si, acumuladas ao final de 182 dias de decomposição (Quadro 2). No quadro 2, encontram-se as quantidades de $\mathrm{Ca}, \mathrm{Mg}$, $\mathrm{K}$ eNa liberadas pelas pal has $\mathrm{s} / \mathrm{Si}$ ec/Si, acumuladas ao final de 182 dias de decomposição. Tanto na areia como no solo, as quantidades liberadas pela palha d Si para os quatro elementos também não foram significativamente diferentes das quantidades liberadas pela palha s/Si.

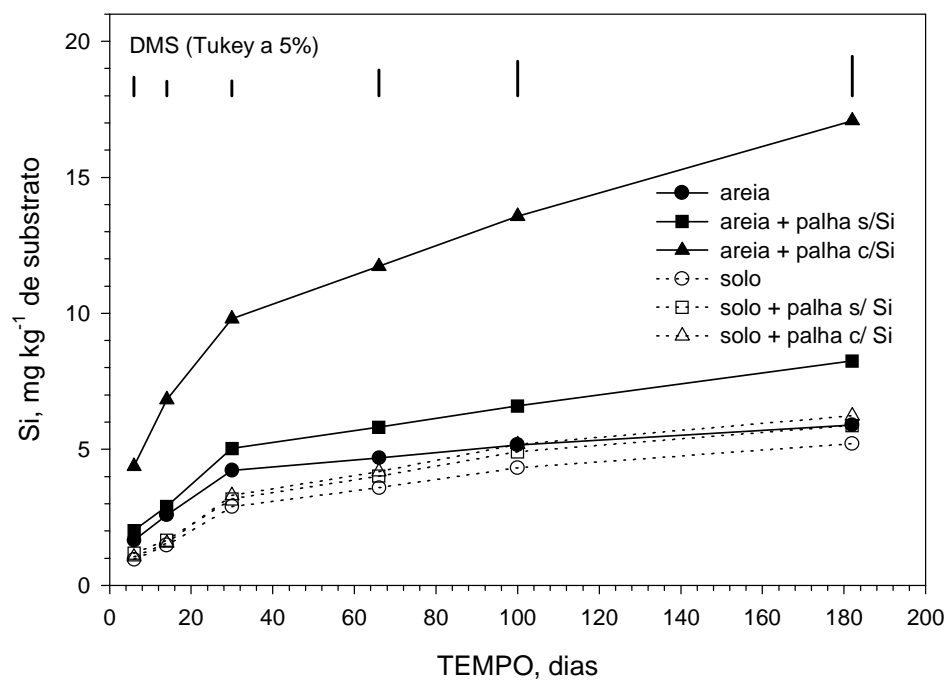

Figura 1. Quantidade de Si liberado com a água de percolação, acumulada de seis coletas durante 182 dias da decomposição de palha de aveia cultivada, com e sem adição de Si (c/Si e s/Si, respectivamente), em tubos que continham areia e solo. 
Quadro 2. Quantidade de C, N, Ca, Mg, K e Na, liberados com a água de percolação, acumulada de seis coletas durante 182 dias da decomposição de palha de aveia cultivada, com e sem Si, em tubos que continham areia e solo

\begin{tabular}{lrrrrrr}
\hline Tratamento & Carbono & Nitrogênio & Cálcio & Magnésio & Potássio & Sódio \\
\cline { 2 - 6 } & \multicolumn{7}{c}{ mg kg-1 de substrato } & & \\
Areia & $9,0 \mathrm{~b}$ & $3,3 \mathrm{~b}$ & $9,0 \mathrm{~b}$ & $2,7 \mathrm{~b}$ & $3,5 \mathrm{~b}$ & $2,3 \mathrm{~b}$ \\
Areia + palha s/Si & $143,4 \mathrm{a}$ & $90,6 \mathrm{a}$ & $24,2 \mathrm{a}$ & $18,8 \mathrm{a}$ & $267,6 \mathrm{a}$ & $25,8 \mathrm{a}$ \\
Areia + palha c/Si & $150,0 \mathrm{a}$ & $103,6 \mathrm{a}$ & $27,0 \mathrm{a}$ & $19,7 \mathrm{a}$ & $274,7 \mathrm{a}$ & $26,9 \mathrm{a}$ \\
Solo & $32,4 \mathrm{a}$ & $36,1 \mathrm{~b}$ & $27,1 \mathrm{~b}$ & $12,1 \mathrm{~b}$ & $8,0 \mathrm{~b}$ & $2,2 \mathrm{~b}$ \\
Solo + palha s/Si & $27,4 \mathrm{a}$ & $123,6 \mathrm{a}$ & $83,8 \mathrm{a}$ & $39,2 \mathrm{a}$ & $109,3 \mathrm{a}$ & $19,9 \mathrm{a}$ \\
Solo + palha c/Si & $29,3 \mathrm{a}$ & $122,9 \mathrm{a}$ & $83,4 \mathrm{a}$ & $39,1 \mathrm{a}$ & $110,0 \mathrm{a}$ & $20,1 \mathrm{a}$
\end{tabular}

Médias seguidas de letras distintas, na mesma coluna e para o mesmo substrato, diferem-se significativamente entre si pelo Teste de Tukey $(P<0,05)$.

Ao contrário do pressuposto e considerando os parâmetros avaliados, o Si presente no tecido de plantas deaveia preta cultivadas em solução nutritiva com adição deste el emento não al ter ou a quantidade de carbono, nitrogênio mineral, cálcio, magnésio, sódi o e potássio li berados com a água de percolação durante o período de 182 dias da decomposição da palha, quando comparado com o tecido de plantas cultivadas sem adição deste el emento.

Esses resultados mostram que, apesar deter sido oSi absorvido pelas plantas e possivel menteter sido depositado na parede celular das células, poderia ainda não encontrar-se como um depósito rígido nas fol has mais jovens (Lewin \& Reimann, 1969) e não causar o efeito esperado. Outra possibilidade estaria relacionada com a pequena quantidade de $\mathrm{Si}$ acumulado pelas plantas de aveia, considerada insuficiente para afetar a decomposição da palha. Dessa forma, o efeito do Si na redução da decomposição somente poderia ser observado em espécies acumuladoras desse el emento, com altos teores de $\mathrm{SiO}_{2}$ no tecido vegetal (como o arroz).

Estudos futuros ainda devem considerar que parte doSi não foi liberada coma água de percolação no período de 182 dias (61\% na areia + palha c/Si), que poderia estar tanto fazendo parteda fase mineral, contribuindo para controlar a disponibilidade de $\mathrm{Si}$ no sistema, como associado ao material orgânico mais recalcitrante que permanece nos substratos (principalmente compostos da parede celular).

\section{CONCLUSÕES}

1. As diferentes concentrações desilício presentes nos tecidos de aveia, cultivada durante 75 dias com e sem adição deste elemento, não alteraram a liberação de carbono enutrientes presentes na água de percolação, durante o período de 182 dias da decomposição da palha.

\section{LITE RATURA CITADA}

DREES, L.R.; WILDING, L.P.; SMECK, N.E. \& SENKAYI, A.L. Silica in soils: quartz and disordered silica polymorphs. In: DIXON, J.B. \& WEED, S.B., eds. Mineral in soil environments. 2.ed. Wisconsin, Soil Science Society of American, 1989. p.913-974.

ELGAWHARY, S.M. \& LINDSAY, W.L. Solubility of silica in soils. Soil Sci. Soc. Am. Proc., 36:439-442, 1972.

HEINEN, W. \& OEHLER, J.H. Evolutionary aspects of biological involvement in the cycling of silica. In: TRUDINGER, P.A. \& SWAINE, D.J ., eds. Biogeochemical cycling of mineralfarming elements. Amsterdan, Elsevier, 1979. p.431-441.

KORNDÖRFER, G.H.; COELHO, N.M.; SNYDER, G.H. \& MIZUTANI, C.T. Avaliação de métodos de extração de silício em sol os cultivados com arroz de sequei ro. R. Bras. Ci. Solo, 23:101-106, 1999.

LEWIN, J . \& REIMANN, B.E.F. Silicon and plant growth. Ann. Rev. Plant Physiol., 20:289-304, 1969.

MA, J . \& TAKAHASHI, E. Release of silicon from ricestraw under flooded conditions. Soil Sci. Plant Nutr., 35:663-667, 1989.

MALAVOLTA, E.; VITTI, G.C. \& OLIVEIRA, S.A. Avaliação do estado nutricional das plantas. Piracicaba, Associação Brasileira para Pesquisa da Potassa e do Fosfato, 1989. 201p.

MARSCHNER, H. Mineral nutrition of higher plants. 2.ed. San Diego, Academic Press, 1995. 889p.

MAYLAND, H.F.; WRIGHT, J.L. \& SOJ KA, R.E. Silicon accumulation and water uptake by wheat. Plant Soil, 137:191-199, 1991.

MIELNICZUK, J . Desenvolvimento de sistemas de culturas adaptadas a produtividade, conservação e recuperação de solos. In: MONIZ, A.C., coord. A responsabilidade social da ciência do solo. Campinas, Sociedade Brasileira de Ciência do Solo, 1988. p.109-116. 
MOORE, T.R. The spectrophotometric determination of dissolved organic carbon in peat waters. Soil Sci. Soc. Am. J ., 49:15901592, 1985

PROVECTO. Métodos para digestão de amostras. Provecto Sistemas Analíticos, s.d. 220p.
TIAN, G.; KANG, B.T. \& BRUSSAARD, L. Biological effects of plant residues with contrasting chemical compositions under humid tropical conditions - decomposition and nutrient release. Soil Biol. Biochem., 24:1051-1060, 1992.

van SOEST, P.J. Limiting factors in plant residues of low biodegradability. Agric. Environ, 6:135-143, 1981. 